Introduction Mental illnesses are common among general population. They are responsible for decreased quality of life, work absenteeism, premature deaths and increasing costs for health systems. Mental diseases can be caused or aggravated by occupational factors and might increase the risk of accidents in the mining industry, if they are not properly detected and treated. The aim of this study was to estimate the association between distress and psychosocial risk at work in a mining company in Valparaiso region, Chile.

Methods A cross-sectional study was conducted during 20142015 in Andina Division, located in Los Andes, Chile. 343 mining workers were invited to participate (response rate 99.7\%), classified according to work-tasks into operative $(n=253)$ and administrative workers $(n=79)$. The adapted survey of Working Conditions and Health in Latin America, GHQ-12 (Goldberg's health questionnaire) of mental symptoms and ISTAS-21 questionnaire of psychosocial risk were applied. The main outcome was distress (GHQ-12 $\geq 5$ ). Descriptive, bivariate (chi ${ }^{2}$ test) and logistic regression (multivariate) analyses controlling for potential confounding factors were performed.

Results Prevalence of distress was 23.6\%. Sensitivity analysis (GHQ-12 $\geq 7$ ) showed a prevalence of potential mental illness of $8.6 \%$. No differences were observed between workers from main company and subcontractors or between operative and administrative workers. Not being able to concentrate (43\%), feeling under stress (43\%) and losing much sleep (35\%) were the most frequently reported. In bivariate analysis, a statistically significant association was found between the presence of distress and high strain jobs $(27.5 \% ; \mathrm{p}=0.02)$. No statistically significant association was found between low job security or type of job and distress. In logistic regression analysis, workers in high strain jobs (OR:2.02; 95\% CI: 1.10 to 3.71) were at increased odds of distress, compared to low strain jobs.

Discussion High strain jobs might be related to distress in Chilean miners. The causes declared for distress could increase the risk of accidents in mining industry.

\section{CONTRIBUTION OF JOB SATISFACTION AND OVERTIME WORK TO MENTAL HEALTH: 1-YEAR FOLLOW-UP STUDY}

\footnotetext{
${ }^{1}$ Masanori Ohta*, ${ }^{2}$ Yoshiyuki Higuchi, ${ }^{3}$ Hisamichi Sugimura, ${ }^{4}$ Masaharu Kumashiro. 'International College of Arts and Sciences, Fukuoka Women's University, Fukuoka, Japan; ${ }^{2}$ Faculty of Education, Fukuoka University of Education, Munakata, Japan; ${ }^{3}$ Kohoku Family Clinic, Tokyo, Japan; ${ }^{4}$ The Association for Preventive Medicine of Japan, Tokyo, Japan
}

\subsection{6/oemed-2018-ICOHabstracts. 1745}

Introduction Overtime work has been suspected as a risk factor for workers' mental distress. A recent cross-sectional study showed that job satisfaction and overtime work could modify the association with mental health in a direct and combined manner (Nakata, 2017). Thus, we have examined the association between job satisfaction and overtime work with mental health using a longitudinal study to explore of causal relationships.

Methods Participants were 1,558 Japanese IT (information technology) workers. Each completed the General Health Questionnaire (GHQ, 28-item version) and Brief Job Stress Questionnaire (BJSQ, index for job strain and job supports) and indicated job satisfaction in 2011 and 2012. Actual amount of overtime work during 3 months in 2011 was recorded by the company. A total of 1408 respondents completed questionnaires and 758 participants were excluded from this analysis because of high GHQ scores (GHQ $>5$, indicating mental distress) in 2011. Finally, 650 participants were used for the evaluation. Risk of mental distress in 2012 by overtime work, job satisfaction, and both combined was estimated by univariable and multivariable logistic regression analysis.

Result Compared to participants with high job satisfaction, those with low satisfaction had increased risk of mental distress in the following year (crude odds ratio (cOR): 1.75), but this difference became insignificant after adjusting for potential confounding factors such as job strain and job supports. Furthermore, there was no significant difference in the risk of mental distress for participants with or without overtime work. However, in the combined analysis, compared to participants with overtime work and high job satisfaction, those with overtime work and low job satisfaction had an increased risk of high GHQ scores (adjusted OR: 2.04).

Conclusion Present longitudinal data suggests that the combination of low job satisfaction and overtime work induces an increased risk of mental distress.

\section{PSYCHOSOCIAL RISKS AND MENTAL HEALTH STATUS IN MANUFACTURING SECTOR WORKERS IN VENEZUELA}

${ }^{1}$ Rodríguez Ilse, ${ }^{2}$ Rojas Maritza*, ${ }^{2}$ Guevara Harold. 'Gente Consultores C.A. Maracay, Venezuela; ${ }^{2}$ Health Sciences Faculty, University of Carabobo, Valencia, Venezuela

\subsection{6/oemed-2018-ICOHabstracts. 1746}

Introduction Occupational Psychosocial Risk Factors (OPRF) studies are a priority because may trig physical/mental healtheffects. National studies confirm international investigations where exposure to unhealthy conditions can constitute a problem. National work regulations emphasise that jobs should achieve psychological well-being. This study identified OPRF in four 'Manufacturing' companies in Venezuela, measuring exposure magnitude associating them with self-perceived mental health.

Methods Observational-descriptive, field study. Psychosocial Risk Assessment was used and CoPSoQ-ISTAS 21, PAST $2.7 \mathrm{c}$ for analysis. Questionnaire evaluates six Dimensions and 20 Factors. Results express exposure's prevalence as the workers proportion in each situation: unfavourable (high risk), intermediate and favourable (low risk).

Results Sample 576 workers. In all DIMENSIONS no high risk was greater than $37 \%$. Social Capital/Compensations had the highest unfavourable situation $(36.78 \%$ and $35.91 \%$, respectively). Employment insecurity (favourable 57.93\%), Working conditions (favourable 57.87\%), Recognition (unfavourable 45.48\%). Emotional demands reported greater risk (41.09\%). Leadership Quality 50.09\% and Predictability $53.34 \%$. $60 \%$ of variables had significant correlation with anxiety/depression.

Discussion and conclusion Psychosocial risks were identified with low magnitudes dimensionally but there were 6 factors in high risk. Siegrist 1996 showed that unbalance Effort/ 